\title{
Vibrational Studies of Calcium Magnesium Ultraphosphate Glasses
}

\author{
Rosli Hussin ${ }^{1, *}$, Musdalilah Ahmad Salim ${ }^{1}$, Nur Shahira Alias ${ }^{1}$, Mutia Suhaibah Abdullah ${ }^{1}$, Suhailah \\ Abdullah ${ }^{1}$, Siti Aishah Ahmad Fuzi ${ }^{1}$, Sinin Hamdan ${ }^{2}$ and Mohd Nor Md Yusuf ${ }^{1}$ \\ ${ }^{1}$ Phosphor Research Group, Department of Physics, Faculty of Science, Universiti Teknologi Malaysia, Skudai, 81310, Johor. \\ ${ }^{2}$ Department of Mechanical and Manufacturing System, Faculty of Engineering, Universiti Malaysia Sarawak, 94300, Kota \\ Samarahan, Sarawak. \\ ${ }^{*}$ Author to whom correspondence should be addressed; E-mail: rbh@dfiz2.fs.utm.my
}

Received: 31 October 2008, Revised: 4 February 2009

Online Publication: 27 May 2009

http://dx.doi.org/10.11113/mjfas.v5n1.286

\section{ABSTRACT}

Phosphate glasses in a system of magnesium calcium phosphate for host matrix luminescent materials were investigated. The glass samples in a series of $x M g O-(40-x) C a O-60 P_{2} O_{5}$ in molar ratio $(0 \leq x \leq 40 \mathrm{~mol} \%)$ were prepared using melt-quenching technique. The effect of $\mathrm{Mg}$ and $\mathrm{Ca}$ content on the structure and glass stability against crystallization in the system of MgO-CaO- $\mathrm{P}_{2} \mathrm{O}_{5}$ ultraphosphate has been investigated using XRD, Infrared and Raman spectroscopy. The compositions containing up to $40 \mathrm{~mol} \%$ of $\mathrm{CaO}$ and /or $\mathrm{MgO}$ formed glasses and no crystalline phases were detected by XRD. The results of IR and Raman spectroscopy suggest that the phosphate network of these glasses is composed of middle $\left(Q^{2}\right)$ and branching $\left(Q^{3}\right)$ phosphate tetrahedral and other calcium/magnesium anions. All the symmetric and asymmetric stretching vibrations of $P O P$ and $\mathrm{PO}_{2}$ observed in the spectra are characteristic of $Q^{3}$ and $Q^{2}$ groups. The glass network, especially the $Q^{2}$ units can be modified by the presence of $C a$ and $M g$ ions. This modification is primarily associated with the phosphate and the $Q^{2}$ and $Q^{3}$ phosphate units randomly distributed in the network. Spectroscopic results shows that the modification of the phosphate network is higher for the Ca containing glasses with respect to the $\mathrm{Mg}$ ones, at the same alkali earth content, due to the well defined $\mathrm{Ca}$ properties as a modifying cation. Formation of $\mathrm{P}-\mathrm{O}-\mathrm{H}$ bond expresses the hygroscopic nature of the phosphate glasses. This study shows that the vibrational spectroscopy (Infrared and Raman) are provide useful, complementary information about the network structures of ultraphosphate glasses.

I X-ray diffraction I Infrared spectroscopy I Raman spectroscopy I Phosphate glasses I Ultraphosphate |

\section{Introduction}

Glasses are increasingly used as host material for solid state lasers based on rare earth and transition metal ionic transitions. The advantages with glasses are the ease with which large homogeneous pieces can be produced. The nonlinear refractive indices can be made low and the doping concentration can be large. It has been shown that the fluorescence intensity of rare earth ion are enhanced several fold when glass hosts with low phonon energies as example in germinate and tellurite are used [1,2]. 
In recent years, phosphate based glasses have been interest due to their several special properties such as large thermal expansion coefficients, low melting temperatures, solubility, etc. [3,4]. It is also an excellent host material due to good chemical durability, ion exchange ability, high gain coefficient, wide band width capability and low upconversion emission. The nonradiative processes include processes characteristic of the host and processes characteristic of the active ion promoted by its concentration. Phosphate glass present high solubility of rare earth ions allowing a high concentration of active ion into a small volume of the phosphate glass [5]. Among oxide glasses, phosphate glasses are particularly attractive hosts because they can accommodate large concentrations of active ions without losing the useful properties of the material. Phosphate glasses are relatively easy to prepare and offer an important range of compositional possibilities (ultra, meta, pyro, and orthophosphate), which facilitate tailoring of the physical and chemical properties of interest for specific technological applications [6,7].

The basic structural units of crystalline and amorphous phosphates are the $\mathrm{PO}_{4}$ tetrahedral and these tetrahedral links through covalent bridging oxygen to form various phosphate anions [8-11]. These tetrahedral are classified using the $\mathrm{Q}^{\mathrm{n}}$ terminology, where $\mathrm{n}$ represents the number of bridging oxygen per tetrahedron $[12,13]$. This notation is usually use in NMR spectra. The networks of phosphate glasses can be classified by the oxygento-phosphorus ratio, which sets the number of tetrahedral linkages, through bridging oxygen, between neighboring P-tetrahedral. Phosphate glasses can be made with a range of structures, from a cross-linked network of $\mathrm{Q}^{3}$ tetrahedral (vitreous $\mathrm{v}-\mathrm{P}_{2} \mathrm{O}_{5}$ ) to polymer-like metaphosphate chains of $\mathrm{Q}^{2}$ tetrahedral to pyro- $\left(\mathrm{Q}^{1}\right)$ and orthophosphate $\left(\mathrm{Q}^{0}\right)$ anions, depending on the modifier composition as shown schematically in Fig. 1.

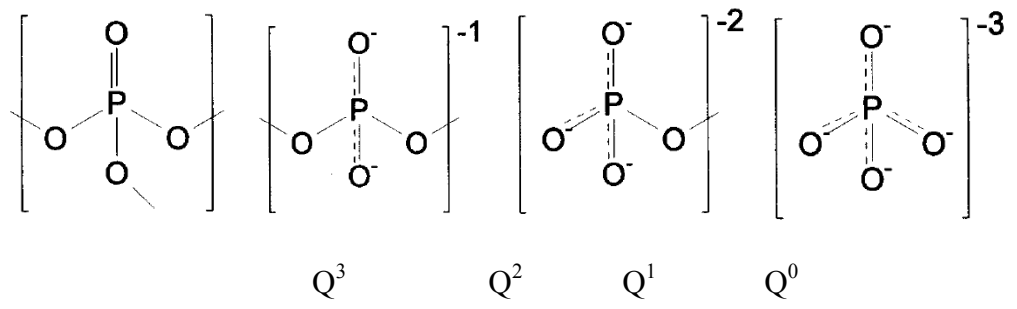

Figure 1: P-tetrahedral sites that can exist in phosphate glasses. [31]

Spectroscopy (IR, Raman and NMR) has been used as an important tool to study the nature of glasses for the past many years. The relative impact of spectroscopy has probably been greater in the analysis of glasses than those of crystals. Galeener and Mikkelsen [14] reported the first Raman spectra from anhydrous v- $\mathrm{P}_{2} \mathrm{O}_{5}$. Due to the $\mathrm{P}_{2} \mathrm{O}_{5}$ is hygroscopic and volatile, anhydrous glasses have been prepared using dry-box handling procedures from crystalline $\mathrm{P}_{2} \mathrm{O}_{5}$ and then melted in sealed silica ampoules. Raman spectra from $\mathrm{P}_{2} \mathrm{O}_{5}$ glass as shown in Fig. 3 are dominated by bands near $1380 \mathrm{~cm}^{-1}$, due to stretching modes of bridging oxygen $\mathrm{P}=\mathrm{O}$, and at $790 \mathrm{~cm}^{-1}$, due to symmetric P-O-P stretching symmetry modes. The intense IR absorption band, around 930 to $970 \mathrm{~cm}^{-1}$ is assigned to asymmetric P-O-P stretching modes [15]. Phosphorus-oxygen, $\mathrm{O}=\mathrm{PO}_{3}$, tetrahedral bonded randomly in a three-dimensional network where in each silicon atom is bonded with four phosphorus atoms by oxygen linkages, and each phosphorus atom has only three such bridging bonds (Fig.1). In the fourth vertex of the $\mathrm{O}=\mathrm{PO}_{3}$ tetrahedron there is a non-bridging oxygen atom bound with the central phosphorus atom with a double bond, $\mathrm{O}=\mathrm{P}$. Owing to a high polarizability of the double bond an intensive band with a maximum at $1380 \mathrm{~cm}^{-1}$ caused by the stretching vibrations of the $\mathrm{O}=\mathrm{P}$ bonds arises in the Raman spectra [10-13].

The addition of a modifying oxide to $\mathrm{v}-\mathrm{P}_{2} \mathrm{O}_{5}$ results in the creation of non-bridging oxygen (NBO) at the expense of bridging oxygen (BO). The resulting depolymerization of the phosphate network with the addition, e.g., of alkali earth oxide, $\mathrm{RO}$, can be described by the pseudo-reaction $2 Q^{n}+R O \rightarrow 2 Q^{n-1}$ [13]. For binary 
$\mathrm{xRO}-(1-\mathrm{x}) \mathrm{P}_{2} \mathrm{O}_{5}$ glasses, the concentrations of $\mathrm{Q}^{\mathrm{n}}$ tetrahedral (Fig. 5) generally follow simple predictions based on the glass composition. In ultraphosphate region, the fractions of Q2 and Q3 tetrahedra are given by NMR study as $f\left(Q^{2}\right)=x /(1-x)$ and $f\left(Q^{3}\right)=(1-2 x) /(1-x)$ [13]. Based on these equation, the composition of this study $(\mathrm{x}=0.40)$, the ratio of $\mathrm{Q}^{3}$ to $\mathrm{Q}^{2}$ is $2 / 3$. The evolution of the cross-linked $\mathrm{Q}^{3}$ network of $\mathrm{P}_{2} \mathrm{O}_{5}$ to the chain-like $\mathrm{Q}^{2}$ network of a metaphosphate glass has be seen clearly in the ${ }^{31} \mathrm{P}$ NMR spectra [16,17]. The bridging-toterminal oxygen ratio, for $\mathrm{xRO}-(1-\mathrm{x}) \mathrm{P}_{2} \mathrm{O}_{5}$ depends on composition according to $B O / T O=0.5(3-4 x)=7$ $[16]$.

The understanding of the glasses structure on different length scales remains difficult mainly due to the lack of periodicity inherent to glasses. Only the suitable correlation of experimental data obtained from several investigations provided by different methods allows the finding of helpful structural information. The use of complementary techniques such as Raman, infrared (IR) and NMR spectroscopy has proven to be an efficient examination way of the glasses structure, in general and of the phosphate glasses structure, in particular.

In this study, basic composition of $60 \% \mathrm{P}_{2} \mathrm{O}_{5}, 0-40 \% \mathrm{CaO}$ and $0-40 \% \mathrm{MgO}$ (all the compositions are referred to mol \%), are chosen as host base glass. The aim of the present work is to investigate the complementary information about the local order around phosphorus tetrahedral structures due to the incorporation of mix alkali earth cation ( $\mathrm{Ca}$ and $\mathrm{Mg}$ ) oxide to ultraphosphates network using both Fourier-transformed infrared (FT-IR) and Raman spectroscopy. The term ultraphosphate refers to compositions where $\mathrm{O} / \mathrm{P}<3.0$. Ultraphosphate glasses in this study, $\mathrm{xRO}-(1-\mathrm{x}) \mathrm{P}_{2} \mathrm{O}_{5}$ systems have $\mathrm{x}<0.5$.

\section{Experimental}

\section{Sample Preparation}

A nominal composition of the glass sample $x M g O-(40-x) C a O-60 \mathrm{P}_{2} \mathrm{O}_{5}$ in $\mathrm{mol} \%$ (with $0 \leq \mathrm{x} \leq 40$ ), were prepared using melt-quenching technique. The batch mixture $(20 \mathrm{~g})$ was prepared using raw materials of reagent grade $\mathrm{CaCO}_{3}, \mathrm{MgO}$ and $\mathrm{H}_{3} \mathrm{PO}_{4}(85 \%$ liquid). The corresponding weights of the starting materials were mixed thoroughly in platinum crucible and placed in air in an electric furnace. A three-step melting schedule was employed to minimize volatilization losses of low-melting starting materials as well as to ensure homogeneous mixing of the constituents. At the first step, the temperature was set to $100{ }^{\circ} \mathrm{C}$ with heating rate of $5{ }^{\circ} \mathrm{C} / \mathrm{min}$, and maintained for $1 \mathrm{~h}$ to facilitate evaporation of water released by $\mathrm{P}_{2} \mathrm{O}_{5}$. The temperature was then raised to $300{ }^{\circ} \mathrm{C}$ (heating rate $=20^{\circ} \mathrm{C} / \mathrm{min}$ ) and left for another $1 \mathrm{~h}$ to release $\mathrm{CO}_{2}$. In the third step, the temperature was increased slowly from 900 to $1250{ }^{\circ} \mathrm{C}$ with heating rate of $10^{\circ} \mathrm{C} / \mathrm{min}$ and kept there for $2 \mathrm{~h}$ in air for the glass to melt. The melts were quickly cooled at room temperature by pouring and pressing between two stainless steel plates to obtain the glass.

\section{Sample Characterization}

The structures of the crystalline and amorphous prepared samples were analyzed by means of X-ray diffraction measurements (XRD), using powders form. The XRD measurements were carried out with $\mathrm{CuK}_{\alpha}$ radiation operating at $40 \mathrm{kV}, 30 \mathrm{~mA}$ with Bragg-Brentano geometry at room temperature using Siemens Diffractometer D5000, equipped with diffraction software analysis. Diffraction patterns were collected in the 2theta $(2 \theta)$ range from 20 to $80^{\circ}$, in steps of $0.04^{\circ}$ and 4 s counting time per step.

To obtain IR absorption spectra of a glass sample, $\mathrm{KBr}$ pellet technique is employed. The glass samples were ground in a clean mortar to a fine powder and weighed quantity $(\sim 4 \mathrm{mg})$ of the powder was intimately mixed with desiccated highly purified $\mathrm{KBr}$ powder. The mixture was then pressed with a pressure of 5 ton per square 
inch to yield a transparent pellet of approximate thickness $0.1 \mathrm{~mm}$ suitable for mounting in the spectrophotometer. All infrared spectra of the glasses were recorded using a Perkin-Elmer Spectrum One FT-IR spectrometer over the range of wavenumber $4000-400 \mathrm{~cm}^{-1}$ at room temperature using $100 \mathrm{scans}$ at $4 \mathrm{~cm}^{-1}$ resolution.

The Raman spectra were measured using Perkin-Elmer model 2000R NIR FT-Raman spectrometer in the spectral range $100-4000 \mathrm{~cm}^{-1}$, with the laser power on the samples being $250 \mathrm{~mW}$. The spectrometer uses an (Nd:YAG) as a lasing medium. The laser is software-controlled, diode-pumped running at $810 \mathrm{~nm}$, with power of $1600 \mathrm{~mW}$ or $750 \mathrm{~mW}$ TEM00 and typical working power range from $100 \mathrm{~mW}$ to $1 \mathrm{~W}$. The resultant Gaussian beam profile is vertically polarized to better than 100:1. The amplitude stability is better than $0.1 \mathrm{rms}$ and is controlled by means of active optical feedback. The laser line width gives a spectral resolution of better than 0.5 $\mathrm{cm}^{-1}$.

\section{Results}

The calcium magnesium phosphate glass samples obtained were transparent and showed no signs of devitrification. XRD spectra of the studied glasses have shown that all the samples are completely amorphous and they do not present any crystalline phase (Fig. 2).

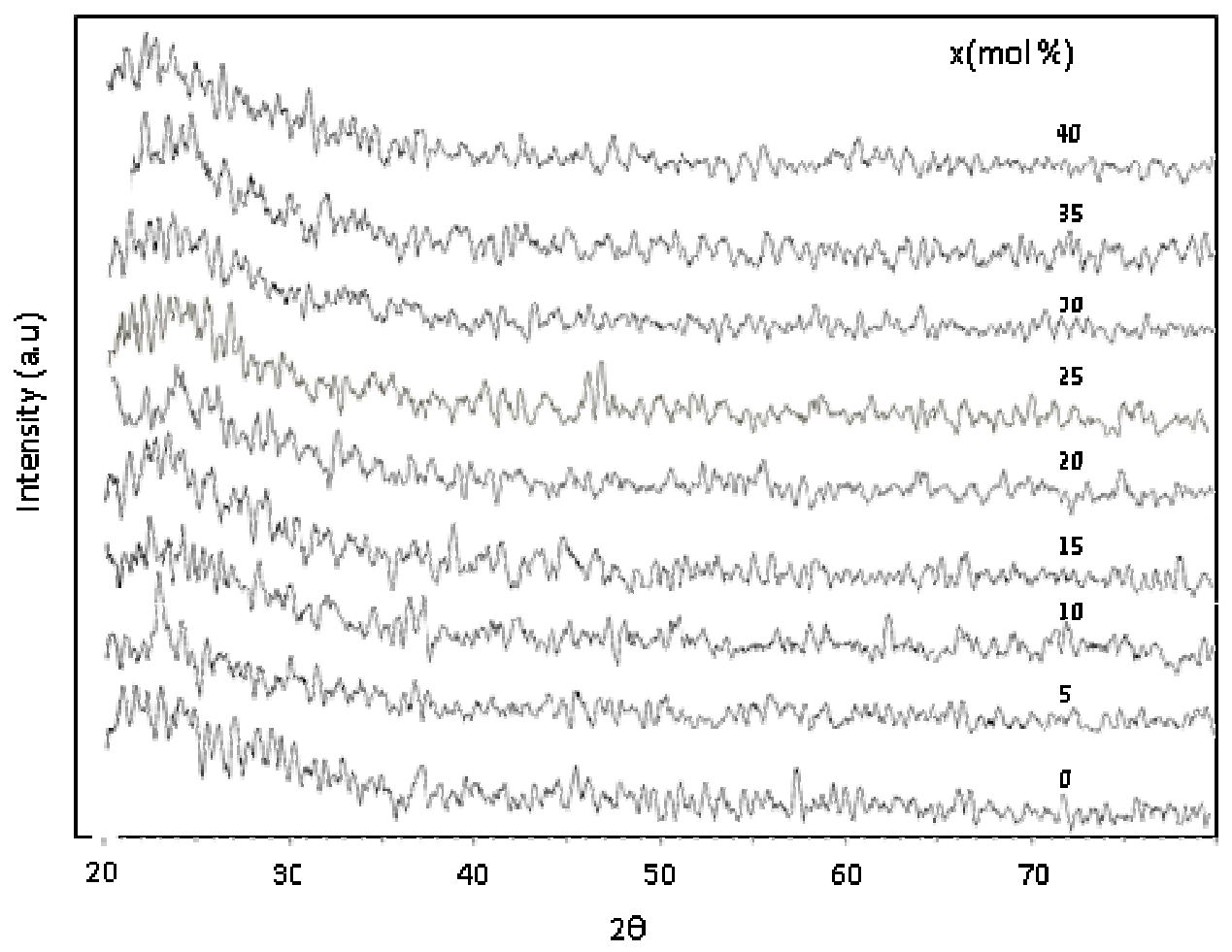

Figure 2: $\mathrm{XRD}$ patterns of $\mathrm{xMgO}-(40-\mathrm{x}) \mathrm{CaO}-60 \mathrm{P}_{2} \mathrm{O}_{5}$ glasses, with $0 \leq \mathrm{x} \leq 0.4$. 


\subsection{Raman Spectra}

Raman spectra of $\mathrm{xMgO}-(40-\mathrm{x}) \mathrm{CaO}-60 \mathrm{P}_{2} \mathrm{O}_{5}$ with compositions in the range $0 \leq \mathrm{x} \leq 40 \mathrm{~mol} \%$ are shown in Fig. 3. The most important bands and their assignments are given in Table 1. The assignment of the peaks was done following guidelines of alkali $(\mathrm{Li}, \mathrm{Na})$ and $(\mathrm{Cu}, \mathrm{Zn})$ ultraphosphate glasses [8,9]. The shapes of Raman spectra of the investigated glasses (Fig. 3) are similar and feature a dominant peaks at around $1320 \mathrm{~cm}^{-1}$ and $1180 \mathrm{~cm}^{-1}$, a shoulder with low intensity around $\sim 1100 \mathrm{~cm}^{-1}$, a shoulder at $792 \mathrm{~cm}^{-1}$, peaks at $\sim 662 \mathrm{~cm}^{-1}$ and a number of bands with weak intensity at $550 \mathrm{~cm}^{-1}, 455 \mathrm{~cm}^{-1}$ and $\sim 300 \mathrm{~cm}^{-1}$. The peaks around $1320 \mathrm{~cm}^{-1}$ is due to the $\mathrm{P}=\mathrm{O}$ symmetric stretch. Bands near $1180 \mathrm{~cm}^{-1}$ are due to the asymmetric stretch of $\mathrm{PO}_{2}$ groups, i.e. stretching motions of the two nonbridging oxygen (NBO) atoms bonded to phosphorous atoms $\left(\mathrm{PO}_{2}\right)$ in the $\mathrm{Q}^{2}$ phosphate tetrahedral (in the $\mathrm{Q}^{\mathrm{n}}$ terminology, $\mathrm{n}$ represents the number of bridging oxygen $(\mathrm{BO})$ per $\mathrm{PO}_{4}$ tetrahedron (will discussion below), and those near $1080 \mathrm{~cm}^{-1}$ are due to the symmetric stretch of $\mathrm{PO}_{2}$ groups. Bands in the frequency region from 655 to $670 \mathrm{~cm}^{-1}$ have been attributed to motions of bridging oxygen in $\mathrm{P}-\mathrm{O}-$ $\mathrm{P}$ chains, originates from the $\mathrm{P}-\mathrm{O}-\mathrm{P}$ symmetric stretch of bridging oxygen in $\mathrm{Q}^{2}$ species whereas the band at 762 $792 \mathrm{~cm}^{-1}$ arises from the asymmetric vibrations of the same species. The broad band at $\sim 300 \mathrm{~cm}^{-1}$ has been assigned to bending vibrations of phosphate network/polyhedral, $\delta(\mathrm{POP})$. The relative intensity of the $\mathrm{P}=\mathrm{O}$ band $\left(1320 \mathrm{~cm}^{-1}\right)$, the intensity of both asymmetric $\left(1180 \mathrm{~cm}^{-1}\right)$ and symmetric $\left(1080 \mathrm{~cm}^{-1}\right) \mathrm{PO}_{2}$ bands slightly decreases with increasing $\mathrm{CaO}$ content. All the frequency of $\mathrm{P}=\mathrm{O}$, symmetric and asymmetric $\mathrm{PO}_{2}$, and symmetric and asymmetric $\mathrm{P}-\mathrm{O}-\mathrm{P}$ band decreases with the addition of $\mathrm{CaO}$.

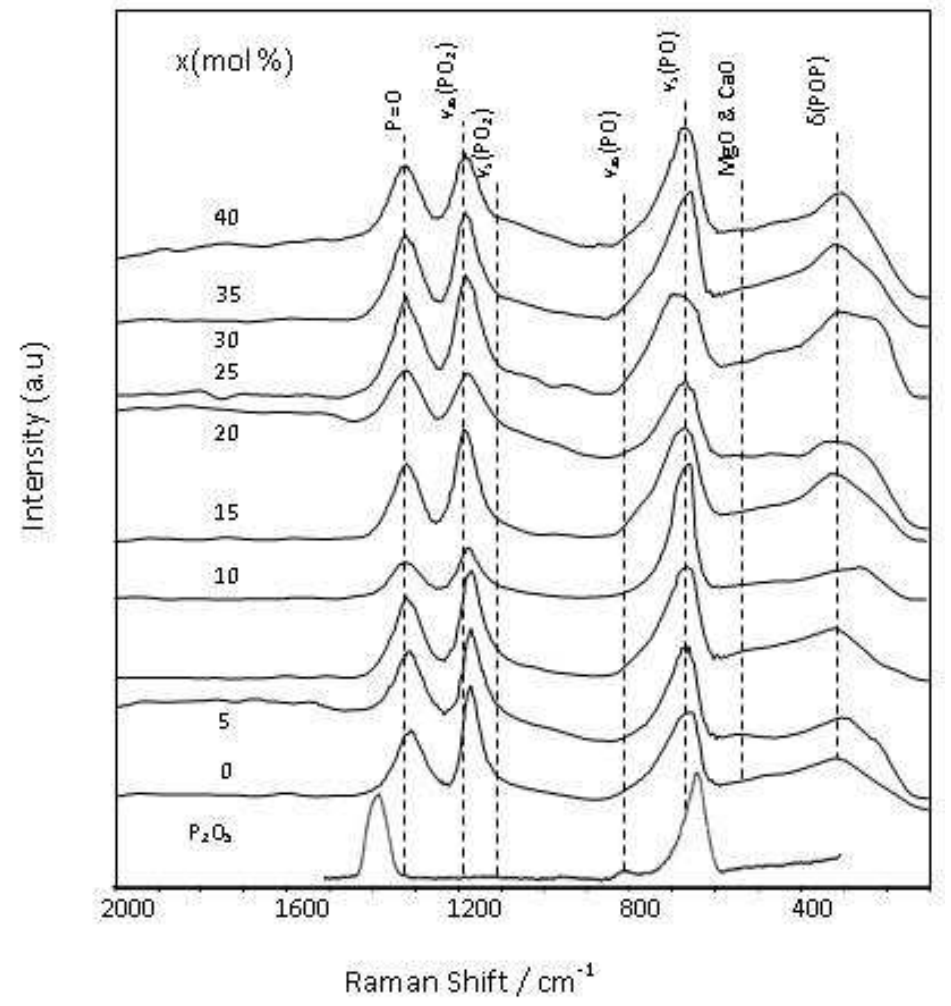

Figure 3: Raman spectra of $x M g O-(40-x) C a O-60 \mathrm{P}_{2} \mathrm{O}_{5}$ with $0 \leq \mathrm{x} \leq 0.4$. 
Table 1: Raman bands and band assignment for $\mathrm{xMgO}-(40-\mathrm{x}) \mathrm{CaO}-60 \mathrm{P}_{2} \mathrm{O}_{5}$ with $0 \leq \mathrm{x} \leq 0.4$.

\begin{tabular}{|c|c|c|c|c|c|c|c|c|c|c|c|c|c|c|c|}
\hline \multicolumn{16}{|c|}{ Frequencies observed and assignments according to Refs $[18,19]$} \\
\hline & \multicolumn{7}{|c|}{ IR } & \multicolumn{8}{|c|}{ Raman } \\
\hline $\mathbf{x}$ & $\begin{array}{l}\delta(\mathrm{MgO} \\
\& \mathrm{CaO})\end{array}$ & $v_{\mathrm{s}} \mathrm{POP}$ & $v_{\mathrm{as}} \mathrm{POP}$ & $v \mathbf{P O}$ & $V_{s} \mathbf{P O}_{2}$ & $v_{a s} \mathrm{PO}_{2}$ & $(\mathbf{P}=\mathbf{O})_{\mathrm{s}}$ & $\delta(\mathrm{POP})$ & $\begin{array}{c}\delta(\mathrm{MgO} \& \\
\mathrm{CaO})\end{array}$ & $v_{\mathrm{s}} \mathrm{POP}$ & $v_{\mathrm{as}} \mathrm{POP}$ & $v \mathrm{PO}$ & $V_{s} \mathbf{P O}_{2}$ & $v_{a s} \mathrm{PO}_{2}$ & $(\mathbf{P}=\mathbf{O}) \mathrm{s}$ \\
\hline$\overline{\mathrm{P}_{2} \mathrm{O}_{5}}$ & - & - & - & & & & & & & 790 & 960 & & & & 1380 \\
\hline 40 & 500 & 640 & 746 & 973 & 1076 & 1180 & 1331 & 302 & $453-545$ & 670 & 789 & 970 & 1089 & 1184 & 1325 \\
\hline 35 & 498 & 643 & 749 & 950 & 1067 & 1175 & 1315 & 314 & $414-533$ & 654 & 768 & 954 & 1086 & 1182 & 1323 \\
\hline 30 & 520 & 650 & 730 & 970 & 1065 & 1160 & 1320 & 306 & $404-470$ & 671 & 780 & 965 & 1085 & 1181 & 1323 \\
\hline 25 & 509 & 655 & 745 & 967 & 1079 & 1156 & 1281 & 284 & $466-551$ & 663 & 774 & 969 & 1082 & 1177 & 1318 \\
\hline 20 & 551 & 662 & 749 & 937 & 1068 & 1176 & 1316 & 322 & $455-550$ & 662 & 762 & 963 & 1080 & 1176 & 1316 \\
\hline 15 & 524 & 665 & 727 & 963 & 1075 & 1157 & 1278 & 314 & $429-588$ & 664 & 775 & 970 & 1079 & 1171 & 1314 \\
\hline 10 & 511 & 660 & 752 & 951 & 1062 & 1163 & 1331 & 316 & $417-511$ & 664 & 780 & 969 & 1077 & 1169 & 1312 \\
\hline 5 & 510 & 620 & 755 & 967 & 1063 & 1175 & 1319 & 300 & $361-543$ & 660 & 785 & 963 & 1074 & 1167 & 1311 \\
\hline 0 & 509 & 659 & 758 & 956 & 1088 & 1124 & 1233 & 315 & $418-483$ & 655 & 792 & 953 & 1073 & 1172 & 1310 \\
\hline
\end{tabular}




\subsection{Infrared Spectra}

The infrared spectra of the $\mathrm{xMgO}-(40-\mathrm{x}) \mathrm{CaO}-60 \mathrm{P}_{2} \mathrm{O}_{5}$ glasses are shown in Fig. 4. The most important bands and their assignments are also listed in Table 1. The typical features of the IR spectrum of the $v-\mathrm{P}_{2} \mathrm{O}_{5}$ glass are $v(\mathrm{P}=\mathrm{O})$ band at $1380 \mathrm{~cm}^{-1}$, the asymmetric stretching band, $v_{\text {asym }}(\mathrm{POP})$ at $960 \mathrm{~cm}^{-1}$ and symmetric stretching bands, $v_{\text {sym }}(\mathrm{POP})$ at $790 \mathrm{~cm}^{-1}$ and no intensity between 1350 and $1200 \mathrm{~cm}^{-1}$ as reported by Mayer [15] are also shown for comparison in Fig. 4. The IR spectra of glasses are consisting of two main sets of infrared absorption bands in the low- and high-frequency regions. The broad bands appear around 3400 and $3150 \mathrm{~cm}^{-1}$. These bands can be accounted for by a different role of $\mathrm{H}_{2} \mathrm{O}$ molecules in the structure. In particular, the atmospheric moisture is easily absorbed by the phosphate sample or by the pellet, causing the appearance of infrared band belonging to $\mathrm{H}_{2} \mathrm{O}$ molecules although the sample under investigation does not contain $\mathrm{H}_{2} \mathrm{O}$ as unit in the network [18]. The three bands located in the range $2700-2950 \mathrm{~cm}^{-1}$ are relatively weak and can be ascribed to the stretching vibrations of $\mathrm{P}-\mathrm{O}-\mathrm{H}$ group in different structural sites. This group forms the strongest hydrogen bonding with the non-bridging oxygen. The strong band at about $1600 \mathrm{~cm}^{-1}$ can be attributed to the $\mathrm{O}-\mathrm{H}$ bending vibration [18].
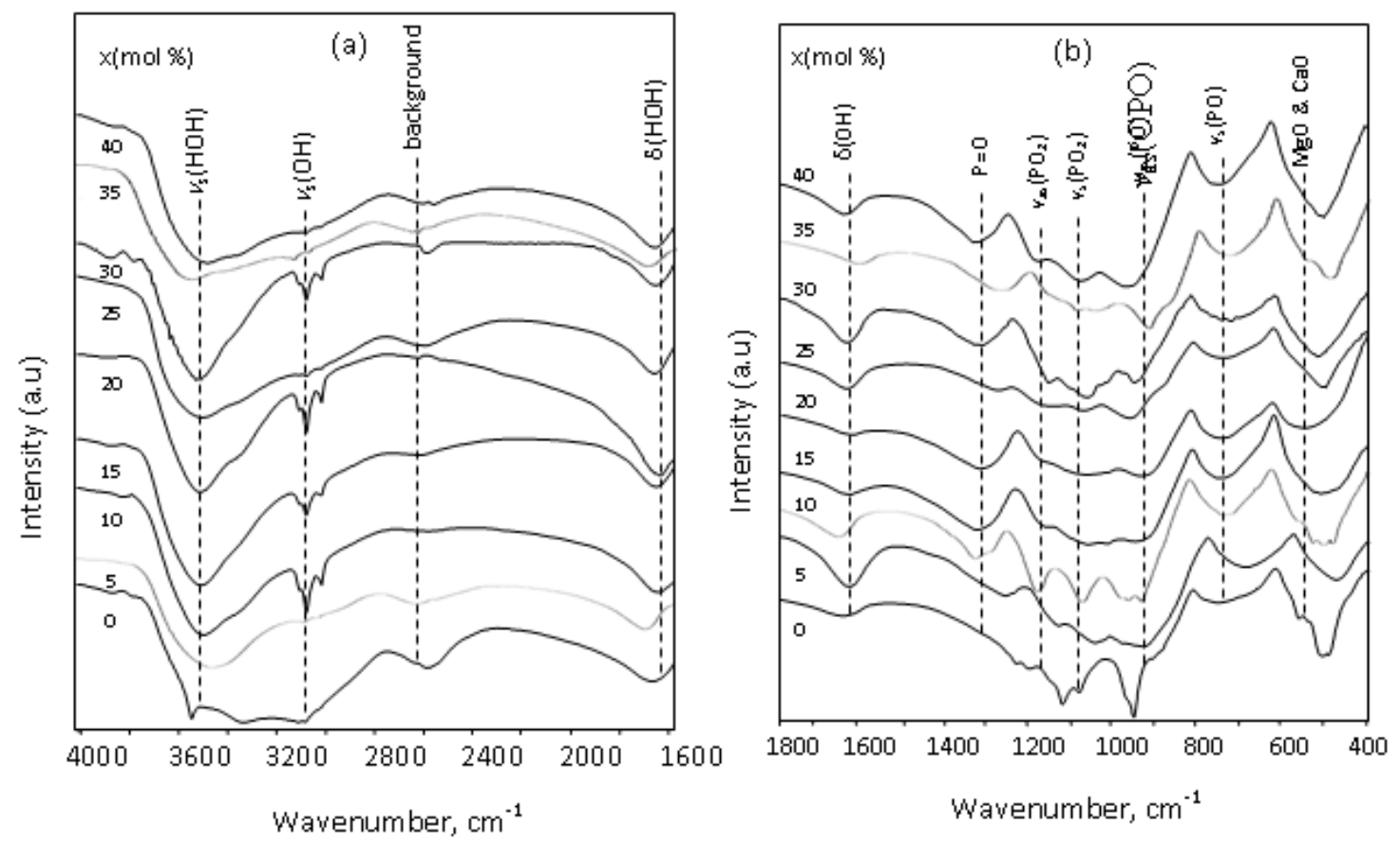

Figure 4: FT-IR spectra of the investigated glasses of $x M g O-(40-x) C a O-60 \mathrm{P}_{2} \mathrm{O}_{5}$, with $0 \leq \mathrm{x} \leq 0.4$ (a) IR spectra in the range of $1600-4000 \mathrm{~cm}^{-1}$ and (b) IR spectra in the range of $400-1800 \mathrm{~cm}^{-1}$. 


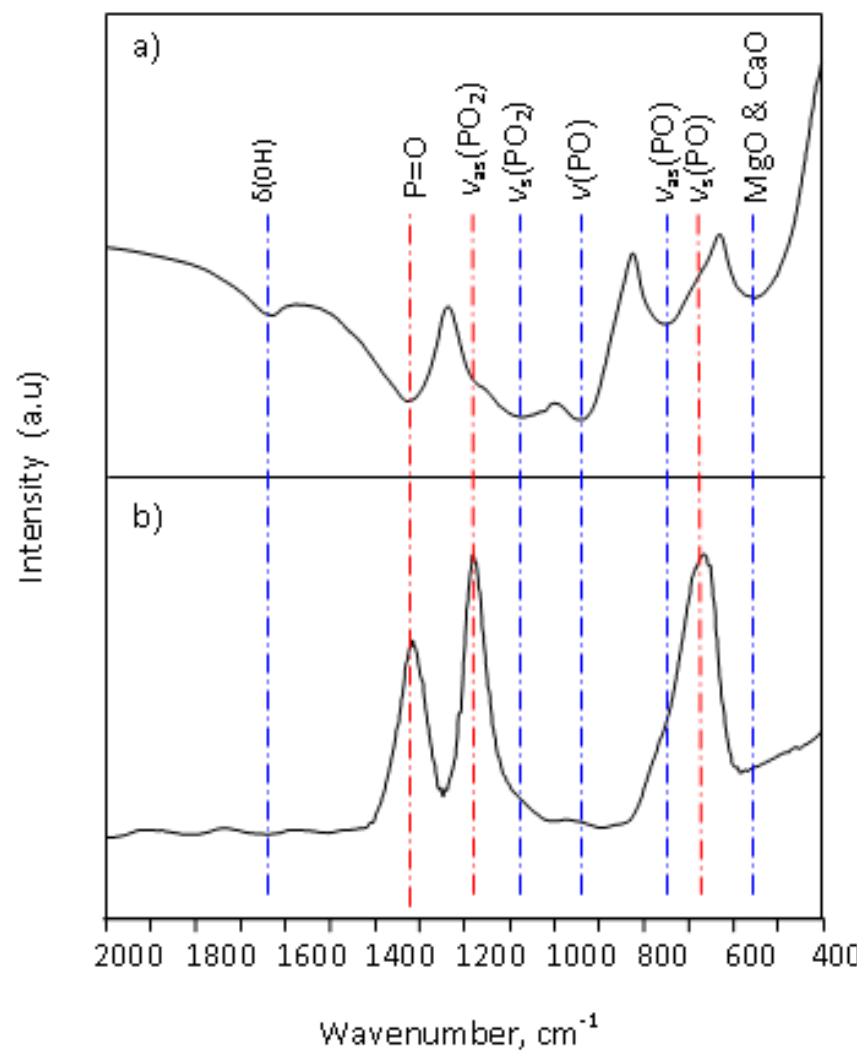

Figure 5: Vibrational spectra of $20 \mathrm{MgO}-20 \mathrm{CaO}-60 \mathrm{P}_{2} \mathrm{O}_{5}$ glass sample, (a) Infrared spectra, (b) Raman spectra.

The bands arising from the vibrations of the phosphate glass network appear in the range $1400-500 \mathrm{~cm}^{-1}$ (Fig. 4(b)). Three main regions can be distinguished in this range; the region between $1400-1150 \mathrm{~cm}^{-1}$ is a characteristic of vibrations of non-bridging $\mathrm{PO}_{2}$ groups, the region around $1150-900 \mathrm{~cm}^{-1}$ is characteristic of terminal $\mathrm{P}-\mathrm{O}$ (and/orPO 3 groups) and the region between 900 and $700 \mathrm{~cm}^{-1}$ is characteristic of the vibrations of bridging $\mathrm{P}-\mathrm{O}-\mathrm{P}$ groups. All the symmetric and asymmetric stretching vibrations observed in the spectra are characteristic of $\mathrm{Q}^{3}$ and $\mathrm{Q}^{2}$ groups.

The assignments for infrared spectra as shown in Fig. 4(b) are more difficult, especially in the range 800$1200 \mathrm{~cm}^{-1}$ due intensity of true peak position, location of peak shoulder and low peak intensity. In order to solve this problem, comparisons between Raman with infrared spectra have been done. Comparisons of Raman and infrared spectra for ultraphosphate glasses are shown in Fig. 5. This figure shows that the advantage and disadvantage of both technique (Raman and infrared) and their complementary each other.

The strong band observed at $1330 \mathrm{~cm}^{-1}$ with its shoulder at $1370 \mathrm{~cm}^{-1}$ is assigned to the characteristic stretching mode of the $\mathrm{P}=\mathrm{O}$ bond. Several previous studies [19-22] have shown that the band corresponding to the stretching vibration of doubly bonded oxygen could be found in the frequency range $1230-1390 \mathrm{~cm}^{-1}$. The band obviously becomes smaller $(x=40)$, indicating a decrease in the double bond character and in the effective force constant of the $(\mathrm{P}=\mathrm{O})$ bond as found in ultraphosphates with increasing the alkali earth content. The band or 
shoulder at about $1160 \mathrm{~cm}^{-1}$ is ascribed to the asymmetric stretching vibration of $\mathrm{O}-\mathrm{P}-\mathrm{O}$ groups, $v_{\text {as }}\left(\mathrm{PO}_{2}\right)$, i.e, to asymmetric stretching modes of the two non-bridging oxygen atoms bonded to phosphorus atoms or $\mathrm{Q}^{2}$ units, in the phosphate tetrahedral. Their intensity obviously increases with increasing $\mathrm{Mg}$ content. This result indicates that the phosphate linkages are shortened as incorporate into the glass structure and leading to increase the relative content of the $\mathrm{Q}^{2}$ units. The medium broad band at $1070 \mathrm{~cm}^{-1}$ is related to the symmetric stretching vibration of that groups, $v_{\mathrm{s}}\left(\mathrm{PO}_{2}\right)[23,24]$. Previous spectroscopic study [24] reported the asymmetric stretching vibration of the metaphosphate group, $v_{\text {as }}\left(\mathrm{PO}_{3}\right)$ end groups $\left(\mathrm{Q}^{1}\right)$, in the range $1080-1180 \mathrm{~cm}^{-1}$. Therefore, in the present IR spectra, the $v_{\text {as }}\left(\mathrm{PO}_{3}\right)$ could interfere with the band at $1160 \mathrm{~cm}^{-1}$. The broadening character observed in the region $900-1100 \mathrm{~cm}^{-1}$ may lead to the assumption that the $v_{\mathrm{as}}\left(\mathrm{PO}_{3}\right)$ could also interfere in the range 1000 $1060 \mathrm{~cm}^{-1}[24]$.

The bands/shoulder around $937 \mathrm{~cm}^{-1}$ is assigned to the asymmetric stretching vibration of $\mathrm{P}-\mathrm{O}-\mathrm{P}$ linkages, $v_{\text {as }}(\mathrm{P}-\mathrm{O}-\mathrm{P})$, while the relatively weak band around $750 \mathrm{~cm}^{-1}$ is due to the symmetric stretching vibration of that linkages, $v_{\mathrm{s}}(\mathrm{P}-\mathrm{O}-\mathrm{P})$, stretching of the bridging oxygen atoms bonded to a phosphorus atom in a $\mathrm{Q}^{2}$ phosphate tetrahedron [23,24]. The asymmetric stretching band of (P-O-P) near $920 \mathrm{~cm}^{-1}$ initially shifts to higher frequencies as the amount of the $\mathrm{Mg}$ increases. The larger wavenumber of the (P-O-P) band is a result of the smaller (P-O-P) bond angle, which results from shorter phosphate linkages or smaller metal cation size. The phosphate linkages of the glasses with higher $\mathrm{Mg}$ content are shorter due to the depolymerization of the glass structure.

On the basis of previous observation [22], the shoulder at about $600 \mathrm{~cm}^{-1}$ can be assigned to a covalent bond between non-bridging oxygen and calcium ions as $\mathrm{P}-\mathrm{O}-\mathrm{Ca}$ stretching vibration. The absorption band at about $550 \mathrm{~cm}^{-1}$ may be assigned either to the harmonics of $\mathrm{P}-\mathrm{O}-\mathrm{P}$ bending vibration or is assigned to harmonics of bending vibration of $\mathrm{O}=\mathrm{P}-\mathrm{O}$ linkages. This band appears in the most binary and ternary phosphate glasses $[25,10]$. All the symmetric and asymmetric stretching vibrations observed in the spectra are characteristic of $Q^{3}$ and $\mathrm{Q}^{2}$ groups.

\section{Discussion}

The results of this studies shown that the phosphate glass structure in the metaphosphate composition, as example in Fig. 3 for $20 \mathrm{MgO}-20 \mathrm{CaO}-60 \mathrm{P}_{2} \mathrm{O}_{5}$, consists of a main network of chains composed of $\mathrm{Q}^{2}$ tetrahedral units, where two of the oxygen atoms are bridging $(\mathrm{P}-\mathrm{O}-\mathrm{P})$ and two are non-bridging $\left(\mathrm{PO}_{2}\right)$. When $\mathrm{CaO}$ and $\mathrm{MgO}$ is added to this group of metaphosphate chains, only little change occurred, as it is revealed from the Raman spectra for both magnesium and calcium phosphate glasses. The $\mathrm{P}=\mathrm{O}$ band $\left(1380 \mathrm{~cm}^{-1}\right.$ in $\mathrm{TeO}_{2}$ glass $)$ shifts to lower frequency $\left(1316 \mathrm{~cm}^{-1}\right)$, and its intensity slightly decreases with increasing $\mathrm{CaO}$ and/or $\mathrm{Mg}$ content. These results show that the changes of the frequencies in various Raman modes are consistent with delocalization.

This assessment of " $\pi$-bonding on $\mathrm{Q}^{3}$ tetrahedral, resulting in longer $\mathrm{P}=\mathrm{O}$ bonds and shorter, and thus stronger, P-BO bonds. Kreidl hypothesized that such delocalization would result in an increased network strength due to the formation of $\mathrm{P}-\mathrm{O}-\mathrm{R}^{2+}$ alkali bridges through the $\mathrm{P}=\mathrm{O}$ bonds on the $\mathrm{Q}^{3}$ species [26]. Similar arrangements are found in the structure of a magnesium ultraphosphate crystal, [8]; the magnesium ions are coordinated to 'double-bonded' oxygen on $\mathrm{Q}^{3}$ tetrahedral as well as non-bridging oxygen on $\mathrm{Q}^{2}$ tetrahedral. As a consequence, the addition of an alkali earth oxide leads to the formation of new alkali-oxygen bridges even as $\mathrm{P}$ $\mathrm{O}-\mathrm{P}$ bridges are eliminated and increase in the strength of the covalent interconnection due to the shorter P-BO bonds. There has been some controversy about the different oxygen species in phosphate glasses, particularly as it relates to the relevance of distinguishing 'double bonded' oxygen from 'nonbridging' oxygen [13]. For example, a $\mathrm{Q}^{2}$ tetrahedron is often represented as possessing one $\mathrm{P}=\mathrm{O}$ and one $\mathrm{P}-\mathrm{O}^{-} \mathrm{R}^{+}$terminal oxygen bond, the 
implication being that the double bond is shorter because of the localization of the fifth valence electron from $\mathrm{P}^{5+}$. This description was supported by an early X-ray photoelectron study [13] in which the O1s spectra from various phosphate glasses were decomposed into three components, representing distinct $\mathrm{P}=\mathrm{O} ; \mathrm{P}-\mathrm{O}^{-} \mathrm{R}^{+}$and $\mathrm{P}-\mathrm{O}-\mathrm{P}$ species. The model of phosphate tetrahedral related in this study is shown in Fig. 6.

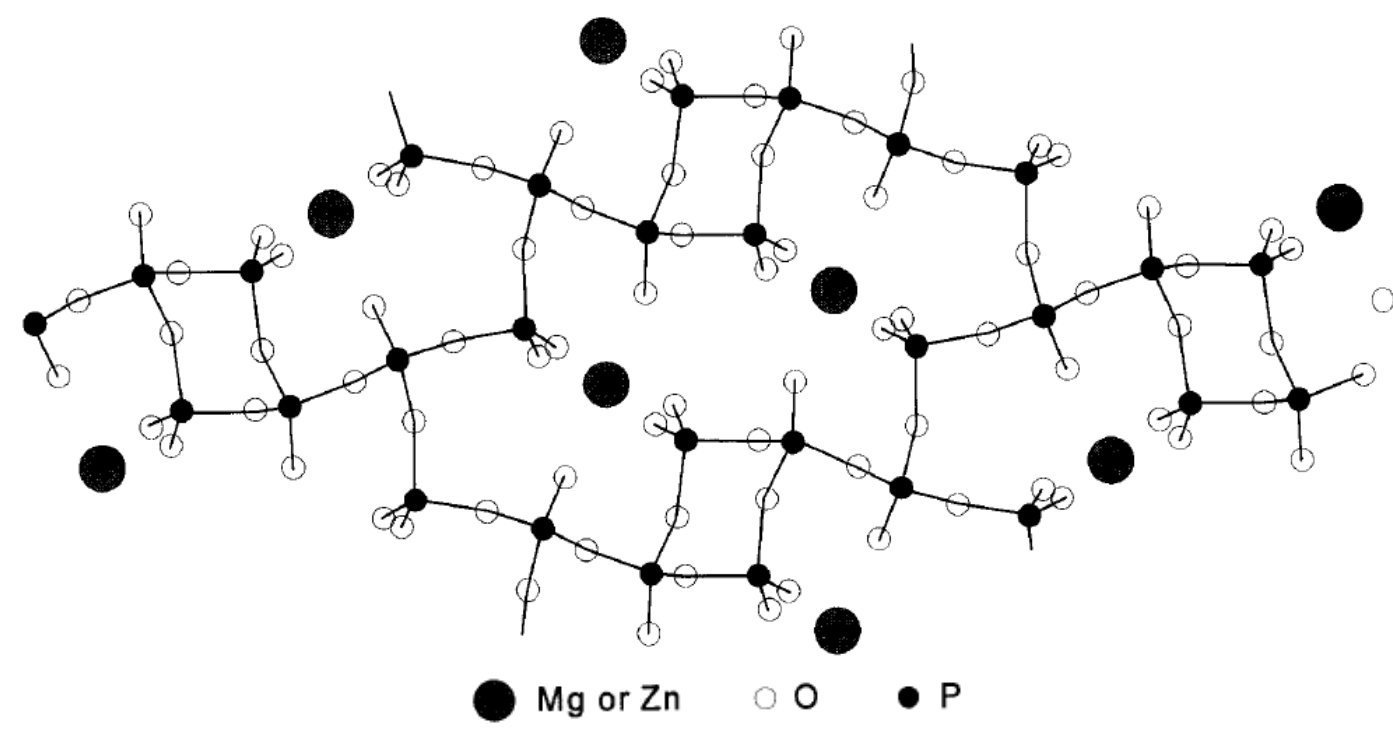

Figure 6: Example model $\mathrm{P}_{2} \mathrm{O}_{5}$ tetrahedral in the crystal structure of $\mathrm{MgP}_{4} \mathrm{O}_{11}$ (taken from Ref. [18]).

The progression from a cross-linked $\mathrm{Q}^{3}$ network, to chain-like $\mathrm{Q}^{2}$ structures, with different alkali/alkali earth ratio has been monitored by a vibrational spectroscopic. As example Fig. 7 is shows the Raman spectra collected from ultraphosphate glasses with the same nominal composition of $60 \mathrm{~mol} \% \mathrm{P}_{2} \mathrm{O}_{5}$, i.e. Li and $\mathrm{Na}$ ultraphosphate [8], Zn-ultraphosphate [11] and Cu-ultraphosphate [10] glasses. The shape of Raman spectra are almost similar, shows that the structure feature in this ultraphosphate glasses are identical each other.

Bands in the $1000-1400 \mathrm{~cm}^{-1}$ range are due to the symmetric and asymmetric stretching modes of Pnonbridging (or terminal) bonds, whereas bands in the $620-820 \mathrm{~cm}^{-1}$ range are due to the symmetric and asymmetric stretching modes of bridging oxygens. For example in $\left(40 \mathrm{Li}_{2} \mathrm{O}-60 \mathrm{P}_{2} \mathrm{O}_{5}\right)$, the frequency of the dominant 'nonbridging' stretching mode decreases from $1380 \mathrm{~cm}^{-1}$ (in $\mathrm{P}_{2} \mathrm{O}_{5}$ glass) to $1360 \mathrm{~cm}^{-1}$ i.e. symmetric $\mathrm{P}=\mathrm{O}$ stretch on $\mathrm{Q}^{3}$ tetrahedral, symmetric $\mathrm{PO}_{2}$ stretch on $\mathrm{Q}^{2}$ tetrahedral, to $1050 \mathrm{~cm}^{-1}$. This decrease in frequency shows the progressive depolymerization of the phosphate network, as well as the increase in the average bond length of P-non-bridging oxygen. 


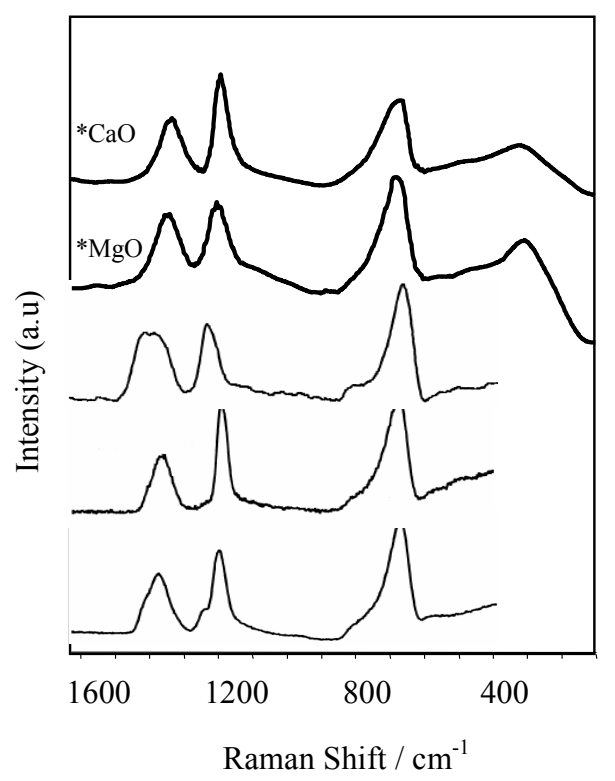

Figure 7: Raman spectra reported for ultraphosphate glasses with $40 \mathrm{~mol} \% \mathrm{Li}_{2} \mathrm{O}, \mathrm{Na}_{2} \mathrm{O}$ [18] and $\mathrm{ZnO}$ [30]. These studies are shown by asterisks.

Even Raman spectra shown in Fig. 7 are similar but their vibration (peak position and width) are different in Li-, Na-, Ca-, Mg-, Cu- and Zn-ultraphosphate glasses, which are related to the expected coordination effects of the different modifiers on the phosphate network. Of particular interest is the presence of separate bands due to the $v(\mathrm{P}=\mathrm{O})$ and $v\left(\mathrm{PO}_{2}\right)_{\text {asym }}$ modes in the spectrum from the $\mathrm{Zn}$-ultraphosphate (and, to a lesser extent, the Liultraphosphate), whereas these two modes are indistinguishable in the spectra from the Ca- and the Naultraphosphate glasses. The smaller $\mathrm{Zn}^{2+}$ ion apparently does not form bonds to terminal oxygen $\mathrm{P}=\mathrm{O}$ on the remaining $\mathrm{Q}^{3}$ tetrahedra which are as strong as those of larger $\mathrm{Ca}^{2+}$ and $\mathrm{Na}^{+}$ions, and so does not affect the frequency of the $\mathrm{P}=\mathrm{O}$ band to nearly the degree found for the other modifying ions.

The frequencies of the $v\left(\mathrm{PO}_{2}\right)_{\text {sym }}$ and $v\left(\mathrm{PO}_{2}\right)_{\text {asym }}$ peaks in Fig. 7, are cation dependent, increasing in frequency as the field strength of the modifying cation increases (in the order $\mathrm{Na}^{+}<\mathrm{Li}^{+}<\mathrm{Ca}^{2+}<\mathrm{Zn}^{2+}$ ), consistent with studies of metaphosphate glasses [27]. The full-width at half maximum (FWHM) of the $v\left(\mathrm{PO}_{2}\right)_{\text {sym }}$ band also increases with increasing cation field strength, from about $25 \mathrm{~cm}^{-1}$ for the $\mathrm{Na}_{2} \mathrm{O}$ glass to about $50 \mathrm{~cm}^{-1}$ for the $\mathrm{ZnO}$ glass, indicating an increase in the degree of disorder that may be due to changes in the distributions of the $\mathrm{Q}^{2} \mathrm{P}-\mathrm{O}$ bond lengths and bond angles. Again, these observations are consistent with previous spectroscopic studies of metaphosphate glasses [28]. Phosphate glasses are composed of $\mathrm{PO}_{4}$ tetrahedral that could be bound to one $\left(\mathrm{Q}^{1}\right.$ species $)$, two $\left(\mathrm{Q}^{2}\right.$ species $)$ and three $\left(\mathrm{Q}^{3}\right.$ species $)$ other tetrahedral through the formation of $\mathrm{P}-\mathrm{O}-\mathrm{P}$ bonds at the tetrahedral corners [13]. The addition of definite amounts of metal ions, such as $\mathrm{Ca}^{2+}, \mathrm{Mg}^{2+}, \mathrm{Na}^{+}, \mathrm{Li}^{+}$, and $\mathrm{Zn}^{2+}$ could produce significant changes of the phosphate glass structure from a three-dimensional random network to long or very short chains of $\mathrm{PO}_{4}$ tetrahedral. 


\section{Conclusions}

This study shows that the vibrational spectroscopy (Infrared and Raman) provide a useful and complementary information about the network structures of ultraphosphate glasses. The structural characterization of the investigated calcium magnesium phosphate glasses by FT-IR and Raman spectroscopy revealed of the spectrum are similar to alkali/alkali earth phosphates with ultraphosphate glass composition. The IR and Raman spectra suggest that the investigated glasses have similar structures consisting of randomly distribution of $\mathrm{Q}^{3}$ and $\mathrm{Q}^{2}$ structural units. All the symmetric and asymmetric stretching vibrations of POP and $\mathrm{PO}_{2}$ observed in the spectra are characteristic of $\mathrm{Q}^{3}$ and $\mathrm{Q}^{2}$ groups. In $\mathrm{P}_{2} \mathrm{O}_{5}$ glass, the glass structure is composed of cross-linked network of $\mathrm{Q}^{3}$ tetrahedral with three bridging oxygen and one isolated doubly bonded oxygen, $(\mathrm{P}=\mathrm{O})$. With the addition of calcium oxide and/or magnesium oxide, a gradual conversion from $\mathrm{Q}^{3}$ to $\mathrm{Q}^{2}$ tetrahedral units occurs. The addition of definite amounts of metal ions, such as $\mathrm{Ca}^{2+}, \mathrm{Mg}^{2+}, \mathrm{Na}^{+}, \mathrm{Li}^{+}$, and $\mathrm{Zn}^{2+}$ could produce significant changes of the phosphate glass structure from a three-dimensional random network to long or very short chains of $\mathrm{PO}_{4}$ tetrahedral. Spectroscopic results shows that the modification of the phosphate network is higher for the Ca containing glasses with respect to the $\mathrm{Mg}$ ones, at the same alkali earth content, due to the well defined Ca properties as a modifying cation.

\section{Acknowledgements}

We would like to acknowledge the financial supports from Ministry of Science Technology and Innovation (MOSTI) under research grant Project Number: 03-01-06-SF0053 and the authors thank Ibnu Sina Institute, Department of Chemistry, Faculty of Science UTM and Faculty of Mechanical UTM for providing the Raman, FT-IR spectroscopy and XRD measurement facilities.

\section{References}

[1] R. Reisfeld, J. Hormadaly, J. Chem. Phys. 64 (1976) 3207.

[2] K. Hirao, S. Kishimomo, K. Tanaka, S. Tanaka, N. Saga, J. Non-Cryst. Solids 151 (1992) 1390.

[3] J.E. Pemberton, L. Latifzahed, J.P. Fletcher, S.H. Risbud, Chem. Mater. 3(1991) 195.

[4] I. Belharouak, C. Parent, B. Tanguy, G. Le Flem, M. Couzi, J. Non. Cryst. Solids 244 (1999) 238.

[5] S. Jiang, T. Luo, B.C. Hwang, F. Smekatala, K. Seneschal, J. Lucas, N. Peyghambarian, J. Non-Cryst. Solids 263\&264 (2000) 364

[6] G.D. Khattak, E.E. Khawaja, L.E. Wenger, D.J. Thompson, M.A. Salid, A.B. Hallak, M.A. Daous, J. NonCryst. Solids 194 (1996) 1.

[7] A.V. Chandrasekhar, R.V.S.S. Ravikumar, B.J. Reddy, Y.P. Reddy, P.S. Rao, Glass Technol. 43 (2002) 32.

[8] J. J, Hudges, R.K. Brow, D.R. Tallant and S.W. Martin, J. Non-Cryst. Solids 223 (1998) 21.

[9] M.A. Karakassides, A. Saranti, I. Koutselas, Journal of Non-Crystalline Solids 347 (2004) 69

[10] P.Y. Shih, S.W. Yung, and T.S. Chin, Journall of Non-Crystalline Solids 244 (1999) 211

[11] K. Meyer, J. Non-Cryst. Solids 209 (1997) 227.

[12] J.R. Van Wazer, Phosphorus and its Compounds, vol. 1\&2, Interscience, New York, 1958.

[13] R.K. Brow, J. Non-Cryst. Solids 263\&264 (2000) 1

[14] F.L. Galeener, J.C. Mikkelsen, Solid State Commun. 30(1979) 505.

[15] K. Mayer, A. Barz and D. Stachel, J. Non-Cryst. Solids, 191(1995)71.

[16] R. Hussin, D. Holand and R. Dupree, Jornal of Non-cryst. Solids, 298 (2002) 32.

[17] M.R. Sahar, A. Wahab M.A. Hussein, R. Hussin, Journal of Non-Cryst., 353(2007)1134.

[18] S.M. Abo-Naf, N.A. Ghoneim, H.A. El-Batal, J. Mater. Sci.: Mater. Electron. 15 (2004) 273.

[19] M. Hafid, T. Jermoumi, N. Toreis, T. Ghailassi, Mater. Lett. 56 (2002) 486. 
[20] T. Jermoumi, S. Hassan, M. Hafid, Vib. Spectrosc. 32 (2003) 207.

[21] E. Metwalli, M. Karabulut, D.L. Sidebottom, M.M. Morsi, R.K. Brow, J. Non-Cryst. Solids 344 (2004) 128.

[22] H. Doweidar, Y.M. Moustafa, K. El-Egili, I. Abbas, Vib. Spectrosc. 37 (2005) 91

[23] A. Chahine, M. Et-tabirou, J.L. Pascal, Mater. Lett. 58 (2004) 2776.

[24] M. Abid, M. Et-tabirou, M. Taibi, Mater. Sci. Eng. B97 (2003) 20.

[25] R.K. Brow, D.R. Tallant, J.J. Hudgens, S.W. Marin, A.D. Irwin, J. Non-Cryst. Solids 177 (1994) 221

[27] N.J. Kreidl, in: N.J. Kreidl, D.R. Uhlmann (Eds.), Glass Science and Technology, Glass-forming Systems, Academic Press, New York, 1983, vol. 1, p. 192.

B.N. Nelson, G.J. Exarhos, J. Chem. Phys. 71 (1979) 2739.

[28] R.K. Brow, C.C. Phifer, G.L. Turner, R.J. Kirkpatrick, J. Am. Ceram. Soc. 74 (6) (1991) 1287. 